\title{
Low program access despite high burden of sexual, structural, and reproductive health vulnerabilities among young women who sell sex in Mombasa, Kenya
}

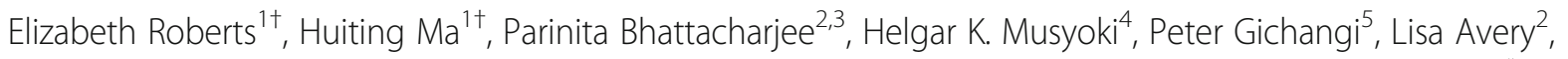
Janet Musimbi ${ }^{3}$, Jenkin Tsang ${ }^{1}$, Shem Kaosa ${ }^{3}$, Japheth Kioko ${ }^{3}$, Marissa L. Becker ${ }^{2}$, Sharmistha Mishra ${ }^{1,6,7,8^{*}} \mathbb{D}^{\text {D }}$, on behalf of the Transitions Study Team

\begin{abstract}
Background: Across Sub-Saharan Africa, young women who sell sex (YSW) face institutional barriers in accessing sexual health and HIV prevention programs designed for female sex workers. In 2018, Kenya developed a national framework to guide service provision for YSW aged 14-24 years. To help inform the implementation of the framework, we estimated the burden of vulnerabilities related to the Sustainable Development Goals (SDGs related to health and gender equality) and program contact among YSW.

Methods: We used data from Transitions, a 2015 bio-behavioural cross-sectional survey of 408 YSW aged 14-24 years in Mombasa, Kenya. We estimated the prevalence of sexual (inconsistent condom use), structural (financial, violence), and reproductive health vulnerabilities; and characterized engagement with local HIV programs tailored to sex workers. We then compared the prevalence of vulnerabilities by age group (14-18 years, $N=117$; 19-24 years, $N=291$ ) and by program contact (ever contacted by local program for sex workers).

Results: $47.3 \%$ reported inconsistent condom use with any partner in the previous week (no difference by agegroup, $p=1.00$ ). Structural vulnerabilities were common and did not vary by age: $83.6 \%$ did not have a regular source of income; 29.9 and $29.2 \%$ had experienced physical and sexual violence, respectively. $26.5 \%$ reported at least one pregnancy before age 18 , and $18.5 \%$ used a non-reliable form of contraception with little variability by age. $25.7 \%$ were aware of at least one program, and only $13.7 \%$ of YSW had ever been contacted by a program (8.5\% of those aged $14-18$ years; and $15.8 \%$ of those aged $19-24$ years, $p=0.06$ ). Sexual, structural, and reproductive health vulnerabilities did not vary by program contact.

(Continued on next page)
\end{abstract}

\footnotetext{
* Correspondence: sharmistha.mishra@utoronto.ca

${ }^{\dagger}$ Elizabeth Roberts and Huiting Ma are co-first authors

'MAP Centre for Urban Health Solutions, Li Ka Shing Knowledge Institute, St.

Michael's Hospital, University of Toronto, Toronto, Canada

${ }^{6}$ Department of Medicine, Division of Infectious Disease, University of

Toronto, Toronto, Canada

Full list of author information is available at the end of the article
}

(c) The Author(s). 2020 Open Access This article is licensed under a Creative Commons Attribution 4.0 International License, which permits use, sharing, adaptation, distribution and reproduction in any medium or format, as long as you give appropriate credit to the original author(s) and the source, provide a link to the Creative Commons licence, and indicate if changes were made. The images or other third party material in this article are included in the article's Creative Commons licence, unless indicated otherwise in a credit line to the material. If material is not included in the article's Creative Commons licence and your intended use is not permitted by statutory regulation or exceeds the permitted use, you will need to obtain permission directly from the copyright holder. To view a copy of this licence, visit http://creativecommons.org/licenses/by/4.0/ The Creative Commons Public Domain Dedication waiver (http://creativecommons.org/publicdomain/zero/1.0/) applies to the data made available in this article, unless otherwise stated in a credit line to the data. 
(Continued from previous page)

Conclusions: SDG-related vulnerabilities begin early in the lives of YSW who are not currently reached by programs designed for female sex workers.

Keywords: Sex work, Kenya, Sustainable development goals, HIV, Sexual health, Reproductive health, Sexual violence, Physical violence, Adolescence, Youth

\section{Background}

In Sub-Saharan Africa (SSA), adolescent girls and young women (AGYW) experience disproportionately high rates of HIV. Women aged 15-24 years bear $26 \%$ of the burden of new HIV infections among adults in SSA [1]. Meanwhile, in Eastern and Southern Africa, women who sell sex are three times more likely to be living with HIV than other women of reproductive age [2]. Although less is known about young women who sell sex (YSW), a growing body of literature from SSA suggests a high incidence and burden of HIV by age 24 among YSW stemming from early experience of sexual, structural, and reproductive health vulnerabilities [3-8].

In Kenya, the median age of AGYW self-identifying as a sex worker or entering sex work ranges from 14 to 18 years, which means the first years of formal sex work occur during adolescence [9, 10]. Many sexual, structural, and reproductive health vulnerabilities reported by YSW in Kenya start as early as first sex and are often associated with entry into sex work at an earlier age [11-15]. Emerging data also suggest that YSW experience higher rates of violence and substance use compared with older women who sell sex [15].

Most HIV prevention and sexual health programs tailored to sex workers are not designed to reach YSW. The United Nations Convention on the Rights of the Child classifies YSW under age 18 years as sexually exploited persons, thereby mandating that states report adolescents who sell sex [16, 17]. While this is an important step to reduce sexual exploitation of children and adolescents, the requirement to report could deter YSW from seeking preventative services - especially those who fear detention for other reasons [15]. Meanwhile, school-based sexual and reproductive health programs may overlook YSW who have terminated their studies and may not sufficiently address vulnerabilities associated with sex work [15]. Prior to 2018 in Kenya, guidance for sex worker programs restricted service provision to women over 17 years of age [18]. Program services include condom promotion, testing and either treatment or referral for treatment of HIV and other sexually transmitted infections, HIV pre-exposure prophylaxis, and violence support programs [19]. Services are delivered in the community by peer educators (former or current sex workers) through outreach as well as at facilities (drop-in centers or clinics) designed specifically for female sex workers [19]. Indeed, emerging data on YSW in Kenya led to development of its 2018 guidelines for service provision to key populations aged 14-24 years and included YSW as mature minors or emancipated minors [18]. Therefore, at the time of this study's data collection in 2015, sexual, structural, and reproductive health services were not tailored to reach or serve YSW in Kenya.

The Sustainable Development Goals (SDGs) are a series of 17 goals set by the United Nations General Assembly in 2015 to be attained for 2030 which serves as a blueprint for improving global health [20]. Several SDG targets address sexual, structural and reproductive vulnerabilities. Kenya has prioritized these targets, including economic empowerment and reduced violence in accordance with SDG-5, which strives to achieve gender equity and empower all women and girls [21]. HIV remains a leading cause of death among women of reproductive age, and the Kenya AIDS Strategic Framework and Kenya's Fast Track Plan to End HIV and AIDS Among Adolescents and Young People align with the goals of SDG-3, which aims to ensure health lives and promote well-being for all at all ages [22, 23]. Although YSW are not explicitly included as a vulnerable group within the population of AGYW, their vulnerabilities are intrinsically linked to the SDGs [15]. Indeed, there is a growing call to understand the unmet needs of YSW to guide gender-responsive approaches that are grounded in human-rights principles to meet the SDGs $[18,24]$.

As sex worker programs across Kenya develop strategies to implement the 2018 recommendations for YSW, we sought to identify the existing SDG-related vulnerabilities and program reach using secondary data from the Transitions study of YSW in Mombasa.

\section{Methods}

Our aims were to: (1) estimate the prevalence of vulnerabilities related to sexual health (inconsistent condom use), structural factors (social economics, violence, and alcohol use), and reproductive health (pregnancy, abortion, and contraception) among YSW in Mombasa, Kenya in 2015; (2) estimate the level of engagement with programs designed for female sex workers in 2015; and (3) determine if vulnerabilities vary by age and by contact with programs designed for female sex workers. 


\section{Study setting and population}

We used data from a behavioural cross-sectional survey, administered between April and November 2015, to women aged 14-24 years who were congregating at sex work venues (hotspots) in Mombasa, Kenya. Sex work venues include any locale where individuals may solicit clients for sex in exchange for money, and could include nightclubs, hotels, bars, guest houses, lodges, restaurants, local brew dens, sex dens and brothels, or streets and other public spaces [25]. Eligibility criteria for the survey included: cis-gender females, aged 14-24 years, who had ever had vaginal or anal sex and were able to provide written informed consent. For the current study on YSW, we restricted our analyses to data on participants who answered yes to at least one of the following questions in the questionnaire: "Presently, do you consider yourself a sex worker?" or "Were you ever a sex worker?"

\section{Study design and data collection}

We identified hotspots using geographic mapping to enumerate the distribution and population size of YSW, which led to the sampling frame and hotspot sampling via probability proportional to estimated YSW population size at each hotspot. Peer/community researchers (i.e. current or former sex workers engaged with local HIV prevention programs) invited potential participants for eligibility screening and consent as detailed previously [11]. Trained interviewers used structured questionnaires to conduct face-to-face interviews in English or Kiswahili. The questionnaire included information on sociodemographic characteristics, sexual behaviours, structural factors, reproductive behaviours and program engagement [11]. The questionnaire was developed for the purpose of this study, and pilot-tested with local community and programmatic input, and data were collected in partnership with the International Centre for Reproductive Health Kenya. Details of the data collection have been detailed previously $[11,25,26]$.

\section{Measures - vulnerabilities}

We selected SDG-relevant vulnerabilities in three domains: sexual health in relation to condom use; structural vulnerabilities; and reproductive health. Vulnerabilities were chosen in accordance with the SDGs and availability of variables collected in the survey. The questions from the survey used to generate each variable are included in Additional file 1.

Sexual vulnerabilities included: inconsistent condom use, defined as at least one encounter (vaginal and/or anal sex) without a condom, with any partner in the previous week. We then defined inconsistent condom use with a paying partner (at least one vaginal and/or anal sex encounter without a condom with a paying partner) and with a non-paying partner (at least one vaginal and/ or anal sex encounter without a condom with a nonpaying partner) among those who had sex with a paying and non-paying partner in the previous week, respectively.

Structural vulnerabilities were conceptualized as per Shannon et al. where factors operating beyond the individual-level influence health and wellbeing [27]. Structural vulnerabilities were divided into: socioeconomic; experience of sexual partner or police violence; and alcohol-related $[2,28,29]$. We defined socioeconomic vulnerabilities as those that limit financial independence: (a) inconsistent (irregular) source of income including sex work; (b) could not fully cover last month's living expenses; (c) did not keep all wage from last month's sex work (i.e. percentage of money from sex work is given to person who arranged the exchange); (d) illiteracy (i.e. cannot read and/or write); (e) has not completed primary school.

Violence-related structural vulnerabilities included: lifetime ("ever") and recent ("past year") experience of physical and sexual violence perpetrated by any sexual partners (clients and non-clients). Police harassment (recent and lifetime) was defined separately as physical abuse or arrest, perpetrated by law enforcement, including the police and "sungu sungu" (community policing groups) [30].

Alcohol- related structural vulnerabilities included: (a) alcohol consumption in past month; (b) inebriation in past month; (c) sex while inebriated in past month; (d) sex with an inebriated partner in past month. Inebriation was defined as reporting self or partner was "drunk" (under the influence of alcohol).

Reproductive health vulnerabilities included: (a) history of adolescent pregnancy, defined as first pregnancy before 18 years of age; (b) history of induced abortion; (c) the most recent induced abortion was unsafe; (d) never used contraception; (e) current use of unreliable contraception. Induced abortions were defined as unsafe if conducted in the absence of trained health workers and/or in the following venues: "[respondent's] home, someone else's home, unlicensed clinic (e.g. quack)" [31]. Safe induced abortions included those conducted in public, private and government health facilities [31]. We defined unreliable contraception as inconsistent and non-modern forms of contraception (i.e "rhythm method", "lactational amenorrhea", "emergency contraception" and "withdrawal") [32].

\section{Definition - program engagement}

Programs refer to local non-governmental organization, community-based organization and/or faith-based organization programs that provide services to female sex workers in Mombasa. We examined various levels of program engagement: (a) aware of a program; (b) ever 
contacted by a program; (c) currently registered in a program; (d) ever used a program clinic; (e) currently working (paid employment) or volunteering as a peer worker in a program. In the questionnaire, items surrounding program registration, clinic use, and status as a peer worker were restricted to participants who had ever been contacted by a program.

\section{Statistical analysis}

We used descriptive statistics to report the prevalence and $95 \%$ confidence intervals (CIs) of vulnerabilities and of program engagement. We compared the difference in prevalence of each vulnerability and of program engagement by age group (14-18 years; $19-24$ years). We also examined the prevalence of vulnerabilities by whether the participant has ever been contacted by programs. We used the $x^{2}$ and Fisher's exact tests for the comparison of proportions as appropriate. We used $\mathrm{R}$ version 3.4.4 for statistical analyses and graphics.

\section{Results}

\section{Participant characteristics (Table 1)}

Of the 1419 women invited to participate, 1304 were eligible, and of whom 1299 provided consent and completed the interview $(91.5 \%$ of those screened, $99.6 \%$ of those eligible). Four hundred and eight self-identified as sex workers, of whom $95.8 \%(N=391)$ identified as current sex workers, and the remaining $(N=17)$ identified as past sex workers.

The median age of participants was 20 years (interquartile range [IQR] $18-22)$; and $28.7 \%(N=117 / 408)$ were between the ages of 14-18 years (Table 1). Few $(6.6 \%, N=27 / 408)$ were ever married. More than half $(59.8 \%, N=244 / 408)$ reported having sex with a nonpaying sexual partner in the past month, with a median of 2 (IQR 1-4) non-paying sexual partners in the past month. The median age of first sex was 15 years (IQR 14-17). The median age at which participants selfidentified as a sex worker was 18 years (IQR 16-20), with a median duration in formal sex work of 2 years (IQR $1-3)$. Four out of five $(80.4 \%, N=328 / 408)$ participants had at least one paying sexual clients in the past month. The median number of paying partners in the previous month was 7 (IQR 4-15). Over half of the participants $(57.4 \%, N=234 / 408)$ had been pregnant at least once.

\section{Program engagement by age (Fig. 1)}

Overall, program awareness and program contact were low (Fig. 1). One quarter of participants $(25.7 \%, N=105 /$ $408)$ were aware of at least one program. 13.7\% $(N=56 /$ 408) were ever contacted by a program, $9.1 \%(N=37 / 408)$

Table 1 Characteristics of women age 14-24 years who sell sex in Mombasa, Kenya (2015)

\begin{tabular}{|c|c|c|c|}
\hline Characteristics & $N=408$ & Median (IQR) & $\%(95 \% \mathrm{Cl})$ \\
\hline \multicolumn{4}{|l|}{ Current age (years) } \\
\hline Median age (IQR) & - & $20(18-22)$ & - \\
\hline \multicolumn{4}{|l|}{ Age-group } \\
\hline $14-18$ & 117 & - & $28.7(24.3-33.1)$ \\
\hline $19-24$ & 291 & - & $71.3(66.9-75.7)$ \\
\hline \multicolumn{4}{|l|}{ Characteristics of sexual partnerships outside of sex work } \\
\hline Ever married & 27 & - & $6.6(4.2-9.0)$ \\
\hline Had at least one non-paying sexual partner in past month & 244 & - & $59.8(55.0-64.6)$ \\
\hline Median number of non-paying sexual partners in past month $(\mathrm{IQR})^{\mathrm{a}}$ & - & $2(1-4)$ & - \\
\hline \multicolumn{4}{|l|}{ Characteristics of sex work } \\
\hline Age of first sex, years & - & $15(14-17)$ & - \\
\hline Age of first paid sex ${ }^{b}$, years & - & $18(16-20)$ & - \\
\hline Duration in sex work, years & - & $2(1-3)$ & - \\
\hline Had at least one paying sexual clients in past month & 328 & & $80.4(76.5-84.2)$ \\
\hline Median number of paying sexual partners in past month $(\mathrm{IQR})^{c}$ & - & $7(4-15)$ & - \\
\hline \multicolumn{4}{|l|}{ Reproductive History } \\
\hline Ever pregnant & 234 & - & $57.4(52.6-62.2)$ \\
\hline Currently has $>=1$ child $^{d}$ & 188 & - & $46.1(41.2-50.9)$ \\
\hline
\end{tabular}

Cl confidence interval, IQR inter-quartile range

${ }^{a}$ Among participants who had at least one non-paying sexual partner in the past month $(N=244)$

${ }^{\text {b}}$ Paid sex is defined as the first time when a participant self-identified as a sex worker

'Among participants who had at least one paying sexual partners in the past month $(N=328)$

dAnswer was $>=1$ to the question: "how many children have you given birth to who are alive, but may or may not live with you" 


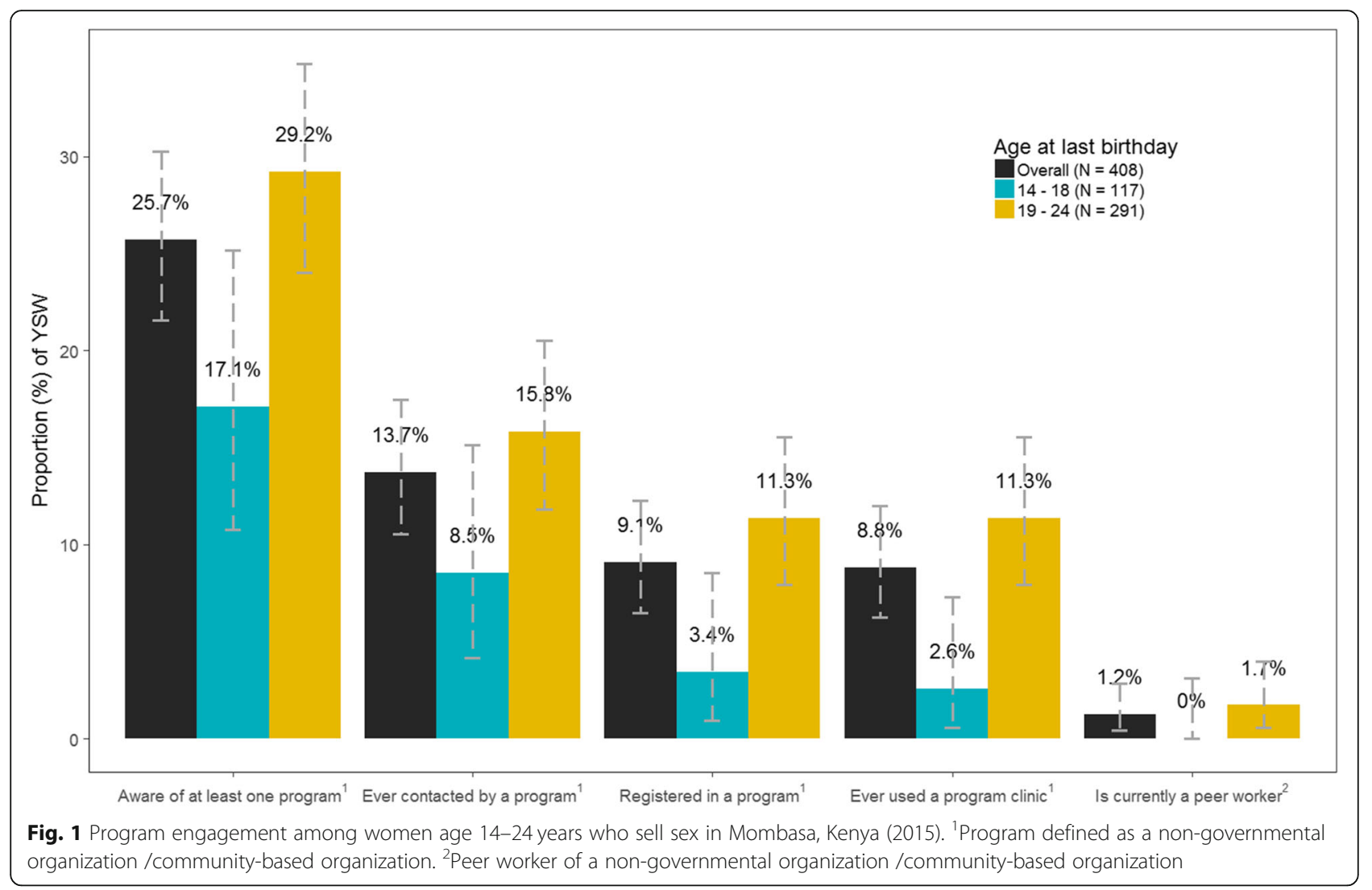

were registered in a program, and $8.8 \%$ had ever used a program clinic $(N=36 / 37 ; 97.3 \%$ of those who were registered). Only $1.2 \%(N=5 / 37 ; 13.5 \%$ of those registered $)$ were peer workers. In general, program awareness $(29.2 \%$ vs. $17.1 \%, p=0.01)$ and program contact $(15.8 \%$ vs. $8.5 \%$, $p=0.06)$ were higher among participants aged 19-24 years compared to those aged $14-18.3 .4 \%(N=4 / 117)$ of participants aged $14-18$ and $11.3 \%(N=33 / 291)$ of participants aged 19-24 were registered with a local program. With respect to later elements of program engagement, among YSW, $2.6 \%$ of those aged $14-18$ years and $11.3 \%$ of those aged 19-24years had ever used a program clinic $(p<0.01)$.

\section{Sexual vulnerabilities by age (Table 2)}

Nearly half of the participants who had sex with any partner in the previous week $(47.3 \%, N=160 / 338)$ reported inconsistent condom use. With respect to inconsistent condom use with at least one sexual encounter, $29.6 \%(N=86 / 291)$ and $55.8 \%(N=115 / 206)$ of participants reported this behaviour with any paying partner and with any non-paying partner respectively. The

Table 2 Inconsistent condom use in the past week among YSW by age group and program contact in Mombasa, Kenya (2015)

\begin{tabular}{|c|c|c|c|c|c|c|c|c|}
\hline \multirow{4}{*}{$\begin{array}{l}\text { Sexual engagement in previous } \\
\text { week, by partner type }\end{array}$} & \multicolumn{8}{|c|}{ Inconsistent condom use in previous week, by partner type ${ }^{\mathbf{a}}$} \\
\hline & \multicolumn{2}{|c|}{ Overall population } & \multicolumn{3}{|l|}{ Age group } & \multicolumn{3}{|c|}{ Program contact $^{\mathbf{b}}$} \\
\hline & & & $\begin{array}{l}14-18 \\
N=117\end{array}$ & $\begin{array}{l}19-24 \\
N=291\end{array}$ & & No, $N=352$ & Yes, $N=56$ & \\
\hline & $\mathrm{n} / \mathrm{N}$ & $\%(95 \% \mathrm{Cl})$ & $\%(95 \% \mathrm{Cl})$ & $\%(95 \% \mathrm{Cl})$ & $p$-value & $\%(95 \% \mathrm{Cl})$ & $\%(95 \% \mathrm{Cl})$ & $p$-value \\
\hline With paying partner $(N=291)$ & $86 / 291$ & $29.6(24.3-34.8)$ & $32.5(22.2-42.8)$ & $28.4(22.3-34.5)$ & 0.56 & $29.8(24.1-35.5)$ & $28.3(15.2-41.3)$ & 0.97 \\
\hline With non- paying partner $(N=206)$ & $115 / 206$ & $55.8(49.0-62.6)$ & $57.7(44.3-71.1)$ & $55.2(47.3-63.0)$ & 0.87 & $56.0(48.6-63.4)$ & $54.8(37.3-72.4)$ & 1.00 \\
\hline With any partner ${ }^{\mathrm{C}}(\mathrm{N}=338)$ & $160 / 338$ & $47.3(42.0-52.7)$ & $47.2(36.8-57.6)$ & $47.4(41.2-53.6)$ & 1.00 & $47.7(42.0-53.5)$ & $45.1(31.4-58.8)$ & 0.84 \\
\hline
\end{tabular}

YSW young women who sell sex, age 14-24 years

${ }^{a}$ Inconsistent condom use defined as at least one encounter (vaginal and/or anal sex) without a condom with any partner of a given type in the previous week

${ }^{b}$ Program contact defined as ever contacted by peers of a non-governmental organization /community-based organization

'Defined as inconsistent condom use during vaginal and/or anal sex with $>=1$ sexual partner in the previous week 
prevalence of inconsistent condom use was similar across the two age-groups, irrespective of partner type (Table 2).

\section{Socioeconomic structural vulnerabilities by age (Table 3 )} Most $(83.6 \%, N=341 / 408)$ participants did not have a regular source of income; $82.4 \%(N=336 / 408)$ reported they could not independently cover their living expenses last month; although only $13.5 \%(N=55 / 408)$ reported they did not keep all their wages. Few participants $(2.7 \%$, $N=11 / 408)$ could not read and/or write and $30.4 \%(N=$ $124 / 408)$ had not completed primary school. There was little variability in socioeconomic vulnerabilities by age, although there was a trend towards lower educational attainment among younger participants (Table 3).

Violence-related structural vulnerabilities by age (Table 3 ) Findings show that 29.9\% ( $N=122 / 408), 29.2 \%(N=119$ / $408)$, and $44.9 \%(N=183 / 408)$ of participants reported ever experiencing physical violence, sexual violence, and police harassment respectively (Table 3 ). Of those, $64.8 \%$ $(N=79 / 408), 48.7 \%(N=58 / 408)$, and $76.0 \%(N=139 /$ 408) experienced physical violence, sexual violence, and police harassment, respectively in the previous year. The prevalence of physical $(30.2 \%[N=88 / 291]$ vs. $29.1 \%$ $[N=34 / 117], p=0.90)$ or sexual violence $(30.9 \%[N=90 /$ $291]$ vs. $24.8 \%$ [ $N=29 / 117], p=0.23$ ) did not vary by age and 29.1 and $24.8 \%$ of participants had experienced physical and sexual violence at least once by age 18 . The prevalence of police harassment was higher among older participants (lifetime experience, $51.2 \%$ [ $N=149 / 291]$ vs. $29.1 \%[N=34 / 117], p<0.01)$.

\section{Alcohol-related structural vulnerabilities by age (Table 3 )} Most (79.4\%, $N=324 / 408)$ participants consumed alcohol in the past month (Table 3 ). Of those who consumed alcohol in the past month, 47.5\% $(N=154 / 408)$ were inebriated at least once in the past month; and $72.7 \%(N=112 / 154)$ reported they were inebriated at least once during sex in the past month. Most $(69.4 \%$, $N=283 / 408$ ) also reported that at least one partner was inebriated during sex in the past month. As with the other structural vulnerabilities, the prevalence of alcohol-related vulnerabilities was similar in the two age-groups $(p>0.05$ for each of the five measures, Table 3).

\section{Reproductive health vulnerabilities by age (Table 4)}

About one in four participants $(26.5 \%, N=108 / 408)$ reported a history of at least one pregnancy during their adolescence. There was a higher prevalence of adolescent pregnancy among younger participants $(37.6 \%[N=$ $44 / 117]$ vs. $22.0 \%$ [ $N=64 / 291], p=0.002)$. Among the 234 participants with a history of pregnancy, $23.9 \%(N=$
56) reported at least one induced abortion in their lifetime. There was little variability by age such that by the age of 18 years, nearly a quarter of participants with a history of pregnancy reported at least one induced abortion. Two-thirds $(66.1 \%, N=37 / 56)$ of the most recent abortions were unsafe; with similar proportions across the age groups. Among those who were using contraception, $18.5 \%(N=62 / 336)$ used a non-reliable form; with little variability by age group.

\section{Vulnerabilities by program contact (Tables 2, 3 and 4)}

In general, there was little variability in the prevalence of sexual, structural and reproductive vulnerabilities by whether or not participants were contacted by local programs (Tables 2, 3, 4; $p>0.05$ across each measure). For example, the prevalence of inconsistent condom use with any partner in the previous week was almost same among participants with and without program contact $(28.3 \%$ vs $29.8 \%, p=0.97)$. There were however a few notable differences with a suggestion of a trend towards higher or lower prevalence of structural and reproductive health vulnerabilities by program contact. For example, participants without program contact were more likely to report a lifetime history of sexual violence (30.4\% vs $21.4 \%, p=0.21$ ) but those with program contact were more likely to report a lifetime history of police harassment $(55.4 \%$ vs $43.2 \%, p=0.11)$. Within the reproductive health domain, there was a trend towards higher prevalence of adolescent pregnancy $(33.9 \%$ vs $25.3 \%, p=0.19$ ) among the small subset of participants who had been contacted by programs versus those who had not.

\section{Discussion}

We found that YSW in Mombasa, Kenya experience a high burden of sexual (inconsistent condom use), structural (social economics, violence, and alcohol use), and reproductive vulnerabilities (pregnancy, abortion, and contraception), alongside low access and engagement in programs tailored for female sex workers. Although the prevalence of a few vulnerabilities, such as police harassment, was more commonly reported by YSW over the age of 18 years, the prevalence of most vulnerabilities was similar across age-groups. YSW under the age of 19 years were nearly half as likely to report program contact compared with YSW aged 19-24; and sexual, structural, and reproductive health vulnerabilities did not vary by program contact.

We examined vulnerabilities relevant to SDG-3 (health and wellbeing) and SDG-5 (gender equity and empowerment), and found that the prevalence of structural and reproductive vulnerabilities was higher than rates reported among AGYW of a similar age in Kenya. Eight in ten women aged 15-19 years surveyed in the household- 


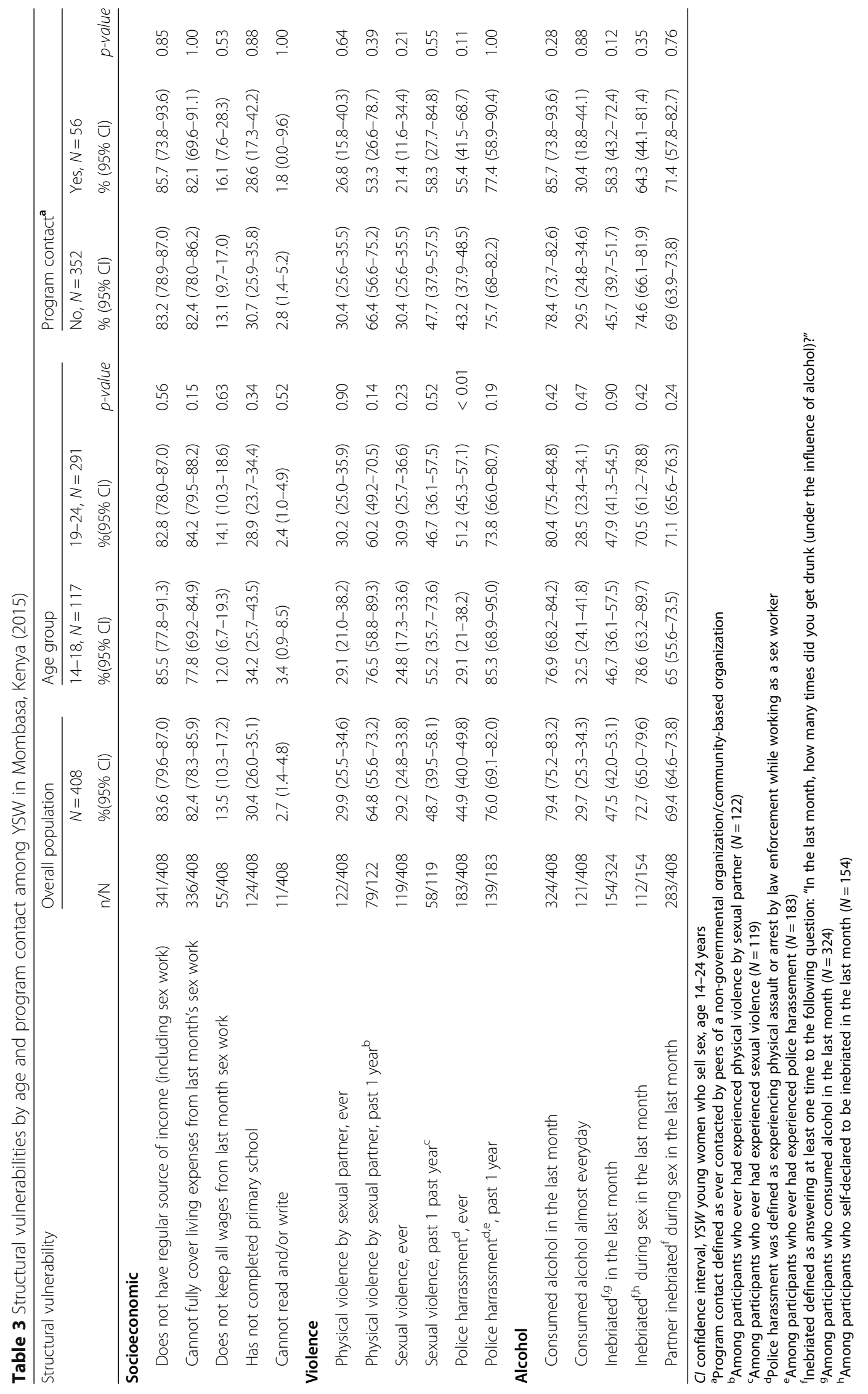


Table 4 Vulnerabilities in reproductive health by age and program contact among YSW in Mombasa, Kenya (2015)

\begin{tabular}{|c|c|c|c|c|c|c|c|c|}
\hline & \multicolumn{2}{|c|}{ Overall population } & \multicolumn{3}{|l|}{ Age group } & \multicolumn{3}{|l|}{ Program contact $^{\mathbf{a}}$} \\
\hline & & & $\begin{array}{l}14-18 \\
N=117\end{array}$ & $\begin{array}{l}19-24 \\
N=291\end{array}$ & & $\begin{array}{l}\text { No, } \\
N=352\end{array}$ & $\begin{array}{l}\text { Yes, } \\
N=56\end{array}$ & \\
\hline & $\mathrm{n} / \mathrm{N}$ & $\%(95 \% \mathrm{Cl})$ & $\%(95 \% \mathrm{Cl})$ & $\%(95 \% \mathrm{Cl})$ & $p$-value & $\%(95 \% \mathrm{Cl})$ & $\%(95 \% \mathrm{Cl})$ & $p$-value \\
\hline Adolescent pregnancy ${ }^{\mathrm{b}}$ & $108 / 408$ & $26.5(22.3-31.0)$ & $37.6(28.8-47.0)$ & $22.0(17.4-27.2)$ & $<0.01$ & $25.3(20.8-30.2)$ & $33.9(21.8-47.8)$ & 0.19 \\
\hline Ever had abortion ${ }^{c}$ & $56 / 234$ & $23.9(18.6-29.9)$ & $23.9(12.6-38.8)$ & $23.9(18-30.7)$ & 1.00 & $23.5(17.8-30.0)$ & $26.5(12.9-44.4)$ & 0.67 \\
\hline Most recent abortion was unsafe ${ }^{d, e}$ & $37 / 56$ & $66.1(52.2-78.2)$ & $81.8(48.2-97.7)$ & $62.2(46.5-76.2)$ & 0.30 & $66.0(50.7-79.1)$ & $66.7(29.9-92.5)$ & 1.00 \\
\hline $\begin{array}{l}\text { Currently using unreliable forms } \\
\text { of contraception, } g\end{array}$ & $62 / 336$ & $18.5(14.4-23.0)$ & $18.1(10.9-27.4)$ & $18.6(13.9-24.1)$ & 1.00 & $17.4(13.1-22.3)$ & $24.1(13.5-37.6)$ & 0.25 \\
\hline
\end{tabular}

Cl confidence interval, YSW young women who sell sex, age 14-24 years

a Program contact defined as ever contacted by peers of a non-governmental organization /community-based organization

${ }^{b}$ Adolescent pregnancy refers to the first pregnancy that occurred before age of 18

${ }^{c}$ Among participants who had a history of pregnancy $(N=234)$

${ }^{\mathrm{d}}$ Among participants who had a history of abortion $(N=56)$

e Unsafe abortion defined as any abortion not performed in public/government/private/non-governmental organization /community-based organization/ faithbased organization facility

${ }^{f}$ Among participants who are currently using any forms of contraception $(N=336)$

gUnreliable forms of contraception are defined as inconsistent and non-modern forms of contraception such as rhythm method, withdrawal, and

emergency contraception

based 2014 Demographic Health Survey reported they lacked employment - similar to the proportion of YSW 14-18 years of age in our study who reported irregular income [33]. However, the prevalence of irregular income was nearly twice as high among YSW aged 19-24 years in our study compared with the $47 \%$ of household survey participants aged 20-24 years who reported they lacked any income [33]. The prevalence of lifetime and of recent sexual violence among YSW in our study was three-fold higher than among 15-24 year old women in the household survey [33]. Three percent of AGYW consumed alcohol in the previous month, compared with nearly 8 in 10 YSW from our study [33]. Reproductive vulnerabilities, such as current use of unreliable contraceptives and adolescent pregnancy was nine-fold and three-fold higher among YSW than reported by $15-$ 24 year old women in the household survey, respectively [33]. Induced abortions were also more common among YSW in our study compared with the national estimates of 38 and 76 per 1000 women aged $15-19$ and $20-24$ years respectively [34]. Taken together, the high prevalence across nearly all SDG-relevant vulnerabilities support earlier findings on heterogeneity in vulnerabilities across AGYW - and thus, this calls for prioritization and tailoring of services to meet the unique needs of this particularly vulnerable subset of AGYW [15].

The high and similar prevalence of lifetime experience of vulnerabilities among YSW across age groups suggests that SDG-relevant vulnerabilities begin early in the sexual life course of YSW and before the age of 18. Cohort effects are variations in characteristic(s) among a group of individuals over time and these individuals are grouped into a cohort based on their shared experience. Within the context of our study, this may have been the case with the trend observed with adolescent pregnancy - the prevalence of which was slightly higher among the 'younger' cohort of YSW born between 1997 and 2001 compared to those born between 1991 and 1996. This suggests that rates of adolescent pregnancy may be increasing over time among YSW. Cohort effects could also be a plausible reason for the higher lifetime prevalence of police harassment among older YSW given the 2014 scale-up of police education to reduce policemediated violence and harassment against sex workers in Kenya [35]. Another reason for the difference in police harassment by age may be the potential for increased visibility of older sex workers to law enforcement. Finally, the high and similar prevalence of recent physical or sexual violence, and of police harassment among those who ever experienced it, across age-groups may be due to ongoing or repeated experience of these vulnerabilities over the sexual life-course of YSW - as previously shown with female sex workers in general across SSA [11, 36].

The potential reasons for the high burden of vulnerabilities among YSW, especially among those aged 1418 years, are complex and inter-related. Age- and gender-based power dynamics with sex partners may be amplified in the context of sex work [14]. There may be fewer social connections with peers in the first few years of sex work leading to less social cohesion - and social cohesion has been associated with higher condom use [37]. Inebriation has been associated with physical and sexual violence perpetrated against AGYW [38] and among female sex workers [39]; and especially in the context of an inebriated partner [39]. Adolescent pregnancy is one of the leading causes of adolescent females dropping out of secondary school in Kenya [40], which in turn may limit their potential to become financially independent and also excludes women from school- 
based sexual and reproductive health education and services [16].

Nearly three in four YSW has yet to access sexual, structural, and reproductive health programs tailored to sex workers. Factors which could limit program engagement among YSW include barriers to self-disclosure to sex work programs and barriers faced by programs in reaching and providing services to YSW. YSW may also experience compounded stigma of being female sex workers as well as sexually-active adolescents or youth potentially obstructing access not only to sex work programs [14], but also to sexual and reproductive health programs for women in general [41]. The 2018 guidelines for HIV programming for young key populations provides an important step in addressing the unmet needs identified in this study [18]. The guidelines deploy a rights-based reframing of services to empower programs to provide services once they reach YSW [18]. Our findings further contribute to the guidelines by providing estimates of the unmet needs with respect to SDG-related vulnerabilities, and signal that a venuebased approach may be helpful in identifying and reaching YSW. Indeed, the venue-based approach used in this survey suggests that YSW who are not currently accessing programs can be reached. And such 'place-based' approaches are now being trialed in other settings to reach YSW $[42,43]$. The challenge thereafter lies in designing and evaluating the components of an effective program to address the unmet sexual, structural, and reproductive health needs of YSW [44]. YSW programming, alongside services for other young key populations, is gaining momentum in Kenya and the next few years will provide evidence to the effectiveness of reaching YSW and reducing vulnerabilities experienced by YSW [18]. Of note, our analysis did not examine use of services external to sex work programs. External services, like traditional clinic-based HIV testing services, would be considered in the design of programs for YSW so that the latter provide synergy and address the residual high prevalence of ongoing vulnerabilities identified in our study.

Study limitations include the use of self-reported data collected via face-to-face-interviews which are subject to recall and social desirability biases, respectively. Recall bias on dates in particular could lead to misclassification of recent experience of vulnerabilities. Social desirability bias could lead to under-reporting of vulnerabilities and potentially over-reporting of program engagement such that program access, while low, could still be an overestimate. We defined YSW based on self-identification as a sex worker; thus we excluded participants who have sex with men in exchange for money or gifts but who do not self-identify as sex workers. Our definition therefore, may lead to underestimating vulnerabilities and program contact. We were limited in our analyses to examining SDG-relevant vulnerabilities based on available data, and thus our findings do not represent the full spectrum of unmet needs among YSW that fall under the SDGs. Moreover, we only considered contact with programs tailored for women engaged in sex work, and not the wider set of services that women may use, such as the public sector family planning services. Important future work includes examining a wider spectrum of SDGs among YSW, access and use of services beyond those tailored for women engaged in sex work, and programmatic and implementation research into how best to reach YSW and address their vulnerabilities.

\section{Conclusion}

In Kenya, there is a high burden of SDG-relevant vulnerabilities among AGYW who sell sex, starting well before the age of 18 years, and current sex work programs are not reaching them. To achieve the SDGs, a pragmatic and rights-based paradigm shift in sexual, structural, and reproductive health services is needed to reduce vulnerabilities at the intersection of adolescence and sex work.

\section{Supplementary information}

Supplementary information accompanies this paper at https://doi.org/10. 1186/s12889-020-08872-6.

Additional file 1. Survey questions from the Transitions Study used for generating variables. A list of survey questions from the Transitions Study that was used for generating variables.

\section{Abbreviations}

AGYW: Adolescent girls and young women; Cl: Confidence interval; IQR: Inter-quartile range; SDG: Sustainable Development Goal; SSA: SubSaharan Africa; YSW: Young women who sell sex

\section{Acknowledgements}

We thank the study participants, field staff, peers and outreach workers, and interviewers. We thank the International Centre for Reproductive Health (Mombasa, Kenya), National AIDS Control Council and the National AIDS \& STI Control Programme (Kenya), Institute for Economics and Forecasting National Academy of Sciences of Ukraine, the Ukrainian Institute for Social Research after Oleksandr Yaremenko (Kyiv, Ukraine) and their respective staff for support in data collection, dissemination, and knowledge translation activities. We thank the Kenya Technical Support Unit for data-entry and data-cleaning support. We thank Dr. Shajy Isac (Karnataka Health Promotion Trust) who led the mapping and enumeration, and Dr. Eve Cheuk (University of Manitoba) who led overall coordination of data collection. We thank all members of the Transitions Study Team. We thank Kristy Yiu (St. Michael's Hospital, University of Toronto) for proof-reading and helping with the submission.

\section{Authors' contributions}

SM and HMa conceived of the study. SM, HMa, ER, and JT designed the study and plan of analyses. HMa conducted the analyses with initial variable selection and preliminary analyses by ER and JT. ER and HMa wrote the first version of the manuscript with revisions by SM. MB, PG, HMu, JM, PB, JK, SK, and SM led data collection. PG and LA contributed to literature review. All authors contributed to study design, interpretation of results, and to critical review and editing of the manuscript. All authors have read and approved the final manuscript. 


\section{Funding}

The study was funded by an operating grant (MOP-13044) from the Canadian Institutes of Health Research (CIHR) and analyses funded via CIHR grant FDN 13455. SM is supported by an Ontario HIV Treatment Network and CIHR New Investigator Award. MB is supported by a CIHR New Investigator Award. ER conducted this research via the St. Michael's. Hospital Keenan Summer Student Program and the University of Toronto Work-Study program (ER). JT conducted this research via the St. Michael's Hospital Keenan Summer Student Program and is now a research professional at Group d'analyse Ltée and the views presented in this article are those of the authors and do not reflect those of Group d'analyse Ltée. None of the funding entities for this research were involved in the design of the study and collection, analysis, and interpretation of data and in writing the manuscript.

\section{Availability of data and materials}

The individual-level data used and/or analysed for the current study, and the $\mathrm{R}$ script for analyses and figures, are available from the corresponding author on request. The external researchers or requesting parties will be asked to sign an Agreement on Confidentiality and Use of Data and will have virtual private network access to the anonymized, individual-level data which are securely stored at the Centre for Global Public Health Data Server at the University of Manitoba.

\section{Ethics approval and consent to participate}

Ethical approval was obtained from the Human Research Ethics Board at the University of Manitoba in Canada (HS16557 [H2013:295]), the Kenyatta National Hospital/University of Nairobi Ethics and Research Committee (P497/10/2013), and the Research Permit Committee of the National Commission for Science, Technology and Innovation, in Kenya. Participants provided written, informed consent prior to participation in study. The rationale for including participants from age 14 years onwards was the early age at which female sex workers reported selling sex for the first time [9] and thus the importance of measuring vulnerabilities and risks experienced during the early period of sex work. The Transitions study was approved by the above ethics review committees to obtain written, informed consent for participation directly from individuals age 14 years and above without the consent of participant's guardians because participants were considered mature minors. The rationale for defining the study population as mature minors included the following: to ensure confidentiality and access to HIV testing and counselling services, the consent procedure for Transitions was in accordance with the Kenya National HIV testing policies which supports HIV testing and counselling to "all or most adolescents under several conditions including showing maturity, of reproductive age, married, pregnant, or engaged in high-risk behavior" [45]. Furthermore, the Transitions study uniquely sampled sexually active individuals who frequented sex work venues (hotspots) and did not sample households; eligible participants may live independently or on the streets and often do not have a legal guardian. Where a legal guardian is present, the guardians may be unaware of participants sexual behaviour and requiring guardian consent may potentially place participants at greater risk of further isolation or harm. As per the Transitions study protocol, participants (and those who declined to participate) were referred to local programmes and clinics, including programmes that tailored services for adolescent girls and young women and those that provided services for female sex workers.

\section{Consent for publication}

Not applicable.

\section{Competing interests}

SM is an associate editor for BMC Infectious Diseases. The rest of the authors declare no conflicts of interest.

\section{Author details}

'MAP Centre for Urban Health Solutions, Li Ka Shing Knowledge Institute, St. Michael's Hospital, University of Toronto, Toronto, Canada. ${ }^{2}$ Centre for Global Public Health, University of Manitoba, Winnipeg, Canada. ${ }^{3}$ Technical Support Unit, Partnership for Health and Development in Africa, Nairobi, Kenya. ${ }^{4}$ National AIDS and STI Control Programme, Nairobi, Kenya. International Centre for Reproductive Health-Kenya, Mombasa, Kenya. ${ }^{6}$ Department of Medicine, Division of Infectious Disease, University of Toronto, Toronto,
Canada. ${ }^{7}$ Institute of Medical Sciences, University of Toronto, Toronto, Canada. ${ }^{8}$ Institute of Health Policy, Management, and Evaluation, University of Toronto, Toronto, Canada.

Received: 25 November 2019 Accepted: 7 May 2020

Published online: 29 May 2020

\section{References}

1. Joint United Nations Programme on HIV/AIDS. UNAIDS Data 2017. Geneva: Joint United Nations Programme on HIV/AIDS; 2017. Available from: https://www.unaids.org/en/resources/documents/2017/2017_data_book. Accessed 1 Nov 2019.

2. Shannon K, Crago AL, Baral SD, Bekker LG, Kerrigan D, Decker MR, et al. The global response and unmet actions for HIV and sex workers. Lancet. 2018; 392(10148):698-710. https://doi.org/10.1016/s0140-6736(18)31439-9.

3. Okafor UO, Crutzen R, Ifeanyi O, Adebajo S, Van Den Borne H. HIV prevalence and high-risk behaviour of young brothel and non-brothel based female sex workers in Nigeria. BMC Res Notes. 2017;10(1):380. https://doi.org/10.1186/s13104-017-2712-8.

4. Busza J, Mtetwa S, Mapfumo R, Hanisch D, Wong-Gruenwald R, Cowan F. Underage and underserved: reaching young women who sell sex in Zimbabwe. AIDS Care. 2016;28(Suppl 2):14-20. https://doi.org/10.1080/ 09540121.2016.1176673.

5. Napierala S, Chabata ST, Fearon E, Davey C, Hargreaves J, Busza J, et al. Engagement in HIV care among young female sex workers in Zimbabwe. J Acquir Immune Defic Syndr. 2018;79(3):358-66. https://doi.org/10.1097/qai. 0000000000001815.

6. Birdthistle I, Tanton C, Tomita A, de Graaf K, Schaffnit SB, Tanser F, et al. Recent levels and trends in HIV incidence rates among adolescent girls and young women in ten high-prevalence African countries: a systematic review and meta-analysis. Lancet Glob Health. 2019;7(11):e1521-e40. https://doi. org/10.1016/s2214-109x(19)30410-3.

7. Chabata ST, Hensen B, Chiyaka T, Mushati P, Mtetwa S, Hanisch D, et al. Changes over time in HIV prevalence and sexual behaviour among young female sex-workers in 14 sites in Zimbabwe, 2013-2016. AIDS Behav. 2019; 23(6):1494-507. https://doi.org/10.1007/s10461-019-02410-1.

8. Bowring AL, Ketende S, Rao A, Mfochive Njindam I, Decker MR, Lyons C, et al. Characterising unmet HIV prevention and treatment needs among young female sex workers and young men who have sex with men in Cameroon: a cross-sectional analysis. Lancet Child Adolesc Health. 2019;3(7): 482-91. https://doi.org/10.1016/s2352-4642(19)30123-3.

9. Musyoki H, Kellogg TA, Geibel S, Muraguri N, Okal J, Tun W, et al. Prevalence of HIV, sexually transmitted infections, and risk behaviours among female sex workers in Nairobi, Kenya: results of a respondent driven sampling study. AIDS Behav. 2015;19(Suppl 1):S46-58. https://doi.org/10.1007/s10461014-0919-4.

10. Kimani J, Kaul R, Nagelkerke NJD, Luo M, Macdonald KS, Ngugi E, et al. Reduced rates of HIV acquisition during unprotected sex by Kenyan female sex workers predating population declines in HIV prevalence. AIDS. 2008; 22(1):131-7. https://doi.org/10.1097/QAD.0b013e3282f27035.

11. Becker ML, Bhattacharjee P, Blanchard JF, Cheuk E, Isac S, Musyoki HK, et al. Vulnerabilities at first sex and their association with lifetime gender-based violence and HIV prevalence among adolescent girls and young women engaged in sex work, transactional sex, and casual sex in Kenya. J Acquir Immune Defic Syndr. 2018;79(3):296-304. https://doi.org/10.1097/qai. 0000000000001826.

12. Parcesepe AM, L'Engle KL, Martin SL, Green S, Suchindran C, Mwarogo P. Early sex work initiation and violence against female sex workers in Mombasa, Kenya. J Urban Health. 2016;93(6):1010-26. https://doi.org/10. 1007/s11524-016-0073-6.

13. Parcesepe AM, L'Engle KL, Martin SL, Green S, Suchindran C, Mwarogo P. Early sex work initiation and condom use among alcohol-using female sex workers in Mombasa, Kenya: a cross-sectional analysis. Sex Transm Infect. 2016;92(8):593-8. https://doi.org/10.1136/sextrans-2016-052549.

14. McClure C, Chandler C, Bissell S. Responses to HIV in sexually exploited children or adolescents who sell sex. Lancet. 2015;385(9963):97-9. https:// doi.org/10.1016/s0140-6736(14)60979-x.

15. Delany-Moretlwe S, Cowan FM, Busza J, Bolton-Moore C, Kelley K, Fairlie L. Providing comprehensive health services for young key populations: needs, barriers and gaps. J Int AIDS Soc. 2015;18(2 Suppl 1):19833. https://doi.org/ 10.7448/ias.18.2.19833. 
16. Global Network of Sex Work Projects. Policy brief: young sex workers. Edinburgh: Global Network of Sex Work Projects; 2016. Available from: https:// www.nswp.org/resource/policy-brief-young-sex-workers. Accessed 1 Nov 2019.

17. United Nations General Assembly. Convention on the rights of the child. New York: United Nations; 1989. Available from: https://www.ohchr.org/en/ professionalinterest/pages/crc.aspx. Accessed 1 Nov 2019.

18. National AIDS \& STI Control Programme. National implementation guidelines for HIV and STI programming among young key populations. Nairobi: Kenya Ministry of Health; 2018. Available from: http://www. childrenandaids.org/node/681. Accessed 1 Nov 2019.

19. National AIDS \& STI Control Programme. National guidelines for HIV/STI programming for key populations. Nairobi: Kenya Ministry of Health; 2014 Available from: https://hivpreventioncoalition.unaids.org/country-action/ kenya-national-guidelines-for-hiv-sti-programming-with-key-populationsoctober-2014/. Accessed 1 Nov 2019.

20. United Nations General Assembly. Transforming our world: the 2030 agenda for sustainable development. New York: United Nations; 2015. Contract No. 16 May. Available from: https://www.un.org/ga/search/view_doc. asp?symbol=A/RES/70/1\&Lang=E. Accessed 1 Nov 2019.

21. United Nations Entity for Gender Equity and the Empowerment of Women. Women and sustainable development goals. Nairobi: United Nations; 2015. Available from: https://sustainabledevelopment.un.org/content/ documents/2322UN\%20Women\%20Analysis\%20on\%20Women\%20and\%2 OSDGs.pdf. Accessed 1 Nov 2019.

22. National AIDS Control Council. Kenya AIDS strategic framework. Nairobi: Kenya Ministry of Health; 2015. Available from: https://www.undp.org/ content/dam/kenya/docs/Democratic\%20Governance/KENYA\%20AIDS\%2 OSTRATEGIC\%20FRAMEWORK.pdf. Accessed 1 Nov 2019.

23. National AIDS Control Council. Kenya's fast-track plan to end HIV and AIDS among adolescents and young people. Nairobi: Kenya Ministry of Health; 2015. Available from: https://vcthealth.org/wp-content/uploads/2017/09/fast-trackplan-to-end-adolescent-aids-and-stigma-fastrack.pdf. Accessed 1 Nov 2019.

24. The Global Fund. Adolescent girls and young women in high-HIV burden settings. Geneva: The Global Fund; 2017. Available from: https://www. theglobalfund.org/media/4576/core_adolescentgirlsandyoungwomen_ technicalbrief_en.pdf. Accessed 1 Nov 2019.

25. Cheuk E, Isac S, Musyoki H, Pickles M, Bhattacharjee P, Gichangi P, et al. Informing HIV prevention programs for adolescent girls and young women: a modified approach to programmatic mapping and key population size estimation. JMIR Public Health Surveill. 2019;5(2):e11196. https://doi.org/10.2196/11196.

26. Ma H, Wang L, Gichangi $P$, Mochache $V$, Manguro G, Musyoki H, et al. Venue-based HIV testing at sex work hotspots to reach adolescent girls and young women living with HIV a cross-sectional study in Mombasa, Kenya. J Acquir Immune Defic Syndr. 2020;Epub ahead of print. https://doi.org/10. 1097/QAI.0000000000002363.

27. Shannon K, Goldenberg SM, Deering KN, Strathdee SA. HIV infection among female sex workers in concentrated and high prevalence epidemics: why a structural determinants framework is needed. Curr Opin HIV AIDS. 2014;9(2): 174-82. https://doi.org/10.1097/COH.0000000000000042.

28. Bourgois P, Holmes SM, Sue K, Quesada J. Structural vulnerability: operationalizing the concept to address health disparities in clinical care. Acad Med. 2017;92(3):299-307. https://doi.org/10.1097/acm.0000000000001294.

29. Baral S, Logie CH, Grosso A, Wirtz AL, Beyrer C. Modified social ecological model: a tool to guide the assessment of the risks and risk contexts of HIV epidemics. BMC Public Health. 2013;13:482. https://doi.org/10.1186/1471-2458-13-482.

30. Canada: Immigration and Refugee Board of Canada. Kenya: the Sungu Sungu group, including activities and areas of operation; actions taken by authorities against the group; state protection available to victims (2010-2013). Canada: Immigration and refugee board of Canada; 2013. Available from: https://www. refworld.org/docid/52a7305f4.html. Accessed 1 Nov 2019.

31. World Health Organization. Clinical practice handbook for safe abortion. Geneva: World Health Organization; 2014. Available from: https://apps.who. int/iris/bitstream/handle/10665/97415/9789241548717_eng.pdf;jsessionid= 6725968D5B854BA2FE9B5F8937E934FE? sequence=1. Accessed 1 Nov 2019.

32. World Health Organization Department of Reproductive Health and Research and Johns Hopkins Bloomberg School of Public Health/Center for Communication Programs. Family planning: a global handbook for providers (2018 edition). Baltimore and Geneva: Center for Communication Programs and World Health Organization; 2018. Available from: https:// www.who.int/reproductivehealth/publications/fp-global-handbook/en/. Accessed 1 Nov 2019.
33. Kenya National Bureau of Statistics. Kenya demographic and health survey 2014. Nairobi: Kenya Ministry of Health; 2014. Available from: https:// dhsprogram.com/publications/publication-fr308-dhs-final-reports.cfm. Accessed 1 Nov 2019.

34. Mohamed SF, Izugbara C, Moore AM, Mutua M, Kimani-Murage EW, Ziraba AK, et al. The estimated incidence of induced abortion in Kenya: a cross sectional study. BMC Pregnancy Childbirth. 2015;15:185. Available from. https://doi.org/10.1186/s12884-015-0621-1.

35. Musyoki H, Bhattacharjee P, Blanchard AK, Kioko J, Kaosa S, Anthony J, et al. Changes in HIV prevention programme outcomes among key populations in Kenya: data from periodic surveys. PLoS One. 2018;13(9):e0203784. https://doi.org/10.1371/journal.pone.0203784.

36. Stockman JK, Lucea MB, Campbell JC. Forced sexual initiation, sexual intimate partner violence and HIV risk in women: a global review of the literature. AIDS Behav. 2013;17(3):832-47. https://doi.org/10.1007/s10461-012-0361-4.

37. Carrasco MA, Nguyen TQ, Barrington C, Perez M, Donastorg Y, Kerrigan D. HIV stigma mediates the association between social cohesion and consistent condom use among female sex workers living with HIV in the Dominican Republic. Arch Sex Behav. 2018;47(5):1529-39. https://doi.org/ 10.1007/s10508-018-1186-7.

38. Selin A, DeLong SM, Julien A, MacPhail C, Twine R, Hughes JP, et al. Prevalence and associations, by age group, of IPV among AGYW in rural South Africa. SAGE Open. 2019;9. https://doi.org/10.1177/2158244019830016.

39. Li Q, Li X, Stanton B. Alcohol use among female sex workers and male clients: an integrative review of global literature. Alcohol Alcohol. 2010;45(2): 188-99. https://doi.org/10.1093/alcalc/agp095.

40. Guttmacher Institute, African Institute for Development Policy. Abortion and unintended pregnancy in Kenya: fact sheet. New York: Guttmacher Institute, African Institute for Development Policy; 2012. Available from: https://www guttmacher.org/sites/default/files/pdfs/pubs/FB_Abortion-in-Kenya.pdf. Accessed 1 Nov 2019

41. Ochako R, Okal J, Kimetu S, Askew I, Temmerman M. Female sex workers experiences of using contraceptive methods: a qualitative study in Kenya. BMC Womens Health. 2018;18(1):105. https://doi.org/10.1186/s12905-018-0601-5.

42. Chiyaka T, Mushati P, Hensen B, Chabata S, Hargreaves JR, Floyd S, et al. Reaching young women who sell sex: methods and results of social mapping to describe and identify young women for DREAMS impact evaluation in Zimbabwe. PLoS One. 2018;13(3):e0194301. https://doi.org/10. 1371/journal.pone.0194301.

43. Herce ME, Miller WM, Bula A, Edwards JK, Sapalalo P, Lancaster KE, et al. Achieving the first 90 for key populations in sub-Saharan Africa through venue-based outreach: challenges and opportunities for HIV prevention based on PLACE study findings from Malawi and Angola. J Int AIDS Soc. 2018;21(Suppl 5):e25132. https://doi.org/10.1002/jia2.25132.

44. United Nations Children's Fund. ayKP Toolkit: United Nations; 2019. Available from: http://childrenandaids.org/aykpToolkit/about. Accessed 1 Nov 2019.

45. National AIDS and STI Control Programme. The Kenya HIV testing services guidelines. Nairobi: Kenya Ministry of Health; 2015. Available from: https:/aidsfree. usaid.gov/sites/default/files/hts_policy_kenya_2015.pdf. Accessed 1 Dec 2019.

\section{Publisher's Note}

Springer Nature remains neutral with regard to jurisdictional claims in published maps and institutional affiliations.

Ready to submit your research? Choose BMC and benefit from:

- fast, convenient online submission

- thorough peer review by experienced researchers in your field

- rapid publication on acceptance

- support for research data, including large and complex data types

- gold Open Access which fosters wider collaboration and increased citations

- maximum visibility for your research: over $100 \mathrm{M}$ website views per year

At $\mathrm{BMC}$, research is always in progress.

Learn more biomedcentral.com/submission 